\title{
SUSCETIBILIDADE DE GENÓTIPOS DE MARACUJAZEIRO-AZEDO À SEPTORIOSE EM CASA DE VEGETAÇÃO' ${ }^{1}$ \\ ANGELA SATHIKO KUDO², JOSÉ RICARDO PEIXOTO, NILTON TADEU VILELA JUNQUEIRA ${ }^{4}$, LUIZ EDUARDO BASSAY BLUM ${ }^{5}$
}

RESUMO - Neste estudo, foi avaliada a reação de genótipos de maracujazeiro-azedo (Passiflora edulis f. flavicarpa) à septoriose (Septoria passiflorae). Para a avaliação da reação dos genótipos, foi utilizado o índice de severidade de doença ( 1 - plantas sem sintomas; 2 - lesões esparsas nas folhas tomando até $10 \%$ do limbo foliar; lesões coalescentes tomando entre 10 a $33 \%$ do limbo foliar; 4 - lesões coalescentes tomando mais de $33 \%$ do limbo foliar; 5 - desfolha) e porcentagem de desfolha. Foi adotado o delineamento de blocos ao acaso, com quatro repetições e seis plantas por parcela, testando-se 60 genótipos. A inoculação foi feita por aspersão de suspensão de esporos $\left(10^{5}\right.$ conídios $\left./ \mathrm{mL}\right)$ patógeno. Foram feitas seis avaliações em intervalos de 7 dias. Os genótipos que apresentaram menor suscetibilidade foram MAR.20.27, Joseph e MAR.20.36. Entre a nota obtida pelo genótipo de menor suscetibilidade $(3,4)$ e o de maior suscetibilidade $(4,5)$, houve diferença de $31,8 \%$, indicando que há variabilidade entre os genótipos para resistência à septoriose. Entre a maior $(81,6 \%)$ e a menor $(49,9 \%)$ porcentagem de desfolha apresentada pelos genótipos, houve diferença de 31,7\%. Os genótipos MAR.20.58 e MAR.20.48 foram os mais suscetíveis, com severidade de 4,5 e 4,6 e de desfolha de $81,6 \%$ e $81,4 \%$, respectivamente.

Termos para indexação: Maracujá, Passiflora edulis f. flavicarpa, septoriose, resistência.

\section{SUSCEPTIBILITY OF PASSIONFRUIT GENOTYPES TO SEPTORIOSIS UNDER GREENHOUSE CONDITION}

\begin{abstract}
The objective of this study was to evaluate the reaction of 60 passionfruit (Passiflora edulis Sims f. flavicarpa Degener) genotypes to septoriosis. The experimental design was randomized blocks with four replications and six plants by plot. The inoculation was made by spraying a pathogen suspension $\left(10^{5}\right.$ conidia $\left./ \mathrm{ml}\right)$ on the plants. Six evaluations were made weekly, 18 days after inoculation. The disease severity was evaluated following the disease index (1, no symptoms; 2 , leaves showing until $10 \%$ of lesion area; 3 , leaves showing 10 to $33 \%$ of lesion area; leaves showing over $35 \%$ of lesion area; 5 , leaf fall) and the percentage of leaf fall. The genotypes which showed less susceptibility were MAR.20.27, Joseph and MAR.20.36, whereas the genotypes MAR.20.59 and MAR.20.48 presented the higher index of susceptibility. Between the score obtained by the less susceptible genotype (3.4) and the score obtained by the most susceptible genotype (4.5) in the lesion scale, there was a difference of $31.8 \%$, indicating that there is variability among the genotypes for resistance to septoriosis. The difference between the highest $(81.6 \%)$ and the lowest (49.9\%) percentage of leaf fall was of $31.7 \%$.
\end{abstract}

Index terms: Yellow passionfruit, Passiflora edulis f. flavicarpa, septoriosis, resistance.

\footnotetext{
'(Trabalho 181-11). Recebido em: 27-06-2011. Aceito para publicação em: 05-12-2011.

${ }^{2}$ Eng. Agr., D.Sc., Analista, CNPq, Brasília-DF, sathiko@cnpq.br, ex-bolsista da CAPES.

${ }^{3}$ Eng. Agr., D.Sc., Professor, FAV/UnB, Brasília-DF, peixoto@unb.br, bolsista do CNPq.

${ }^{4}$ Eng. Agr., D.Sc., Pesquisador, Embrapa-Cerrado, Brasília-DF, junqueir@cpac.embrapa.br, bolsista do CNPq.

${ }^{5}$ Eng. Agr., Ph.D., Professor, Fitopatologia/UnB, Brasília-DF, luizblum@unb.br, bolsista do CNPq.
} 


\section{INTRODUÇÃO}

Nos últimos anos, a longevidade do ciclo produtivo do maracujazeiro-azedo (Passiflora edulis Sims e P. edulis Sims f. flavicarpa Degener) tem reduzido consideravelmente. Este problema está associado principalmente a um fungo, fenômeno denominado morte precoce ou morte prematura do maracujazeiro, que é caracterizado pela baixa longevidade das plantas de um pomar, e é relacionado a vários agentes patogênicos. Um dos patógenos relacionados a esse mal que vem destacando-se nos últimos anos é o fungo Septoria passiflorae Sydow, principalmente na região dos Cerrados. Este fungo também causa manchas e queima nas folhas, bem como severa desfolha das plantas (FISCHER; REZENDE, 2008; NASCIMENTO et al., 2000).

A ocorrência desta enfermidade nos pomares de maracujazeiro tem levado ao aumento no custo de produção, devido à necessidade de aplicação de medidas de controle (JUNQUEIRA et al., 2003). Além disso, a preocupação crescente de consumidores com a qualidade mercadológica e com a preservação ambiental, o que tem levado ao aumento na procura de produtos sem resíduos de agrotóxicos, que podem ser obtidos através do uso de cultivares resistentes, associado a técnicas de manejo adequado. Assim, uma vez que essa cultura não apresenta ainda uma cultivar homogênea, produtiva e tolerante aos principais problemas fitossanitários, incluindo a septoriose, trabalhos relacionados ao melhoramento genético visando à resistência à doenças faz-se necessário (FISCHER, 2002; REZENDE, 2008; AMATA et al., 2009; EL-MOOR, 2002).

Desta forma, o objetivo deste trabalho foi selecionar genótipos para que possam ser usados como fonte de resistência ao fungo causador da septoriose em maracujazeiro-azedo.

\section{MATERIAL E MÉTODOS}

Foi utilizado um isolado de $S$. passiflorae obtido a partir de plantas severamente afetadas, mantidas em casa de vegetação, na Estação Experimental de Biologia da Universidade de Brasília, no Distrito Federal. O isolamento foi feito em placas de Petri com BDA com $250 \mathrm{mg} / \mathrm{L}$ de cloranfenicol, e a multiplicação do patógeno, em meio de BDA. As placas foram mantidas em incubador $\left(25^{\circ} \mathrm{C}\right)$ sob fotoperíodo de $12 \mathrm{~h}$, durante 7 a 10 dias. A multiplicação do fungo foi feita sob as mesmas condições descritas para o isolamento. Para a obtenção da suspensão do inóculo, foi feita a raspagem dos conídios em picnídios produzidos no meio de cultura com uma alça de metal, e posteriormente foram triturados em liquidificador com água esterilizada $\left(121^{\circ} . \mathrm{C}, 1 \mathrm{~atm}\right.$ por 20 minutos). A estimativa da concentração do inóculo foi efetuada com auxílio de uma câmara Neubauer.

A semeadura dos genótipos de maracujazeiro foi feita em bandejas de poliestireno, com substrato à base de casca de Pinus sp. e vermiculita, produto comercial Plantmax ${ }^{\circledR}$, utilizando-se de duas sementes por célula.

O delineamento utilizado foi em blocos ao acaso, com quatro repetições de seis plantas por parcela. Os tratamentos foram formados por 60 genótipos: Yellow Master FB100, Yellow Master FB200 (utilizadas como testemunhas suscetíveis), Redondão, EC-3-0, EC-2-0, EC-7-L, PES-09 e PES-07, MAR-20-01, MAR-20-02, MAR-20-03, MAR-20-04, MAR-20-05, MAR-20-06, MAR-2007, MAR-20-08, MAR-20-09, MAR-20-10, MAR20-11, MAR-20-12, MAR-20-13, MAR-20-14, MAR-20-15, MAR-20-16, MAR-20-17, MAR-2018, MAR-20-19, MAR-20-20, MAR-20-21, MAR20-22, MAR-20-23, MAR-20-24, MAR-20-25, MAR-20-26, MAR-20-27, MAR-20-28, MAR-2029, MAR-20-30, MAR-20-31, MAR-20-32, MAR20-33, MAR-20-34, MAR-20-35, MAR-20-36, MAR-20-37, MAR-20-38, MAR-20-39, MAR-2040, MAR-20-41, MAR-20-42, MAR-20-43, MAR20-44, MAR-20-45, MAR-20-46, MAR-20-47, MAR-20-48, MAR-20-49, MAR-20-50, MAR-20-59 e o genótipo Joseph. Os genótipos foram obtidos a partir de trabalhos de seleção e cruzamentos desenvolvidos pela Embrapa Cerrado e Universidade de Brasília, levando em consideração os aspectos de produtividade, qualidade dos frutos e resistência aos principais patógenos.

A inoculação foi feita quando as mudas apresentaram 8 a 11 folhas verdadeiras. A aplicação de conídios foi feita através de pulverização da suspensão nas faces abaxial e adaxial das folhas.

Um experimento foi realizado para determinar a concentração ideal do inóculo $\left(10^{4}, 10^{5} \mathrm{e}\right.$ $10^{6}$ conídios $/ \mathrm{mL}$ ) a ser utilizado no experimento posterior, onde foram testados seis genótipos em blocos ao acaso, com quatro parcelas de 12 plantas (Tabela 1), onde se constatou melhor concentração a $10^{5}$ conídios $/ \mathrm{mL}$. Tal experimento também foi usado para determinar a melhor variável para a avaliação da septoriose.

No experimento, foi utilizada a concentração de $10^{5}$ conídios $/ \mathrm{mL}$, determinada através dos resultados apresentados na Tabela 1, em 60 genótipos (Tabela 2). Após a inoculação, foi utilizado um termo-higrógrafo para registro da temperatura e da umidade relativa do ar, onde se podem verificar 
temperaturas médias de 25 a $28^{\circ} \mathrm{C}$, durante o dia, e de 19 a $22^{\circ} \mathrm{C}$, durante a noite, e a umidade relativa do ar de $\sim 91 \%$. As mudas dos diferentes genótipos foram mantidas em câmara úmida por 16 dias, até o aparecimento dos sintomas da doença.

Foram realizadas seis avaliações, sendo a primeira no $18^{\circ}$ dia após a inoculação e as demais a intervalos de sete dias. Para a quantificação da doença, foram utilizadas duas variáveis, índice de severidade de doença e porcentagem de desfolha por parcela, utilizado o índice proposto por Dias (1990), com adaptações: (1) plantas sem sintomas; (2) lesões esparsas nas folhas tomando até $10 \%$ do limbo foliar; (3) lesões coalescentes tomando entre 10 a $33 \%$ do limbo foliar; (4) lesões coalescentes tomando mais de 33\% do limbo foliar; e (5) desfolha.

Em função do índice de severidade de doença, foram consideradas como resistentes $(\mathrm{R})$ as plantas com médias entre 1 e 2; medianamente resistentes (MR), as plantas com médias entre 2 e 3 ; suscetíveis (S), as plantas com médias entre 3 e 4 ; e altamente suscetíveis (AS), as plantas com médias maiores que 4. Para cada avaliação, calculou-se a porcentagem de plantas resistentes por genótipo.

Os dados coletados foram submetidos à análise de variância ( $\mathrm{P}=5 \%$ de probabilidade de erro). As médias foram comparadas entre si pelo teste de Tukey $(\mathrm{P}=5 \%)$. Foram feitas análises de regressão e análises de correlação linear entre as variáveis avaliadas, baseando-se na significância de seus coeficientes.

\section{RESULTADOS E DISCUSSÃO}

Na avaliação da reação de genótipos de maracujazeiro ao fungo $S$. passiflorae, pode-se observar diferença entre genótipos em relação às variáveis estudadas quanto à severidade da doença e porcentagem de desfolha. Em ambos os parâmetros, os resultados foram semelhantes, onde as médias aumentaram em função do tempo, com diferenças significativas nas avaliações iniciais e finais (Figura 1). Os resultados das duas variáveis de severidade da doença foram semelhantes, indicando uma correlação positiva entre as mesmas.

A concentração de inóculo não subestimou ou superestimou as variações nos níveis de suscetibilidade dos genótipos e, portanto, foi usada no ensaio para a avaliação dos 60 genótipos, foi de $10^{5}$ conídios/mL (Tabela 1). Também se verificou que esta concentração de inóculo permitiu concluir-se que a melhor variável para avaliar a reação de genótipos foi a severidade. Em contraste, Pinto (2002) obteve diferentes níveis de resistência ao aplicar a concentração de $1,5 \times 10^{6}$ conídios $/ \mathrm{mL}$ de $S$. passiflorae em plantas de maracujazeiro. Enquanto Dias (1990) relatou que a concentração que apresentou maior coalescimento de lesões e maior desfolha foi a de $10^{4}$ conídios $/ \mathrm{mL}$, sendo mais severa que a concentração de $10^{5}$ conídios $/ \mathrm{mL}$, considerada a mais indicada para obter alto índice de doença para testes de fungicidas em casa de vegetação. Tais diferenças podem associar-se aos isolados do patógeno, indicando a possibilidade de existência de isolados mais virulentos.

Verificou-se que nenhum genótipo apresentou resistência à septoriose quanto à severidade de doença (Tabelas 1 e 2). Houve variação no nível de suscetibilidade. Os genótipos que apresentaram menor severidade de doença para essas variáveis foram MAR.20.27, Joseph e MAR.20.36, classificados como suscetíveis, e o genótipo MAR.20.59 que apresentou maior severidade de doença (Tabela 2), juntamente com os 25 genótipos, classificados como altamente suscetíveis (Tabela 2). Apesar de não ter havido genótipo resistente à septoriose, houve diferença significativa entre os genótipos para o índice de severidade de doença, que variou de 3,40 no genótipo menos suscetível a 4,48 no genótipo mais suscetível, representando uma diferença de $31,76 \%$, indicando que há variabilidade entre os mesmos.

Resultados semelhantes foram obtidos por Bueno et al. (2007), conduzindo trabalho com 48 genótipos de maracujazeiro-azedo em casa de vegetação, classificando-os como suscetíveis à septoriose e com diferenças estatísticas entre os mesmos. Os genótipos MAR. 20.16, MAR. 20.53 e MAR. 20-60 foram considerados os menos suscetíveis à doença. Contudo, a escala de notas e a concentração de inóculo usada pelos autores foi distinta das aqui apresentadas.

As cultivares Yellow Master FB100 e Yellow Master FB200, no presente trabalho, foram classificadas como suscetíveis à doença, assim como os híbridos EC-3-0 e EC-2-0, sendo que não diferiram estatisticamente entre si. Junqueira et al. (2003), estudando cultivares de maracujazeiro em campo, não observaram diferença entre os dois últimos genótipos, utilizando escala em três níveis de classificação de resistência em frutos (resistente, suscetível e altamente suscetível), classificando-os como suscetíveis, assim como a cultivar Redondão. Neste trabalho, essa cultivar foi considerada altamente suscetível à doença em folhas de miúdas, evidenciando o baixo grau de resistência desses genótipos.

Pinto (2002) relatou que os genótipos MAR.20.50 e EC-2-0 apresentaram o maior número de plantas resistentes, enquanto, neste trabalho, o primeiro genótipo foi classificado como altamente 
suscetível, com $69 \%$ de desfolha. Tal resultado indica segregação do material, quando há necessidade de novos ciclos de seleção para verificar a resistência do genótipo.

Sousa (2009), avaliando 26 progênies sob condições de campo, verificou moderada suscetibilidade em todas as progênies, incluindo MAR.20.01, MAR.20.06, MAR.20.10, MAR.20.12, MAR.20.15, MAR.20.19, MAR.20.21, MAR.20.24, MAR.20.29, MAR.20.34, MAR.20.39, MAR.20.40, MAR.20.41, MAR.20.44, PES 9, Yelow Master FB 100, Yelow Master FB 200, EC-3-0, Redondão e ECL 7. Avaliando diversas progênies em condições de campo, Bouza (2009) verificou moderada suscetibilidade em todos os materiais, incluindo EC-RAM, AR 01, AR 02, AP 1, Yelow Master FB 200, MAR.20.03, MAR.20.23, MAR.20.36 e MAR.20.46. Trabalhando com 14 genótipos de maracujazeiro-azedo em campo, Coimbra (2010) verificou moderada resistência nos genótipos AR 01, AR 02, AP 1, MAR.20.46, MAR.20.03, MAR.20.09, EC-RAM e Vermelhão Ingaí.
A variação dos valores do índice de severidade de doença e de porcentagem de desfolha em função do tempo foi estimada através de regressão linear (Figura 1). Conforme as equações [severidade $(\%)=0,26$ tempo $+3,07, \mathrm{r}^{2}=0,91$; desfolha $(\%)=7,59$ tempo + $\left.39,43, r^{2}=0,88\right]$, os dados indicam que a doença ainda se encontrava em progresso, não atingindo o ponto de máxima no final das avaliações. Independentemente das variáveis estudadas para avaliar a resistência dos genótipos ao fungo S. passiflorae, houve diferentes níveis de reações dos genótipos ao patógeno, o que pode ser um indicativo de resistência parcial do maracujazeiro à doença. No entanto, para se certificar da variabilidade para resistência encontrada nos genótipos menos suscetíveis, faz-se necessário estudo em condições de campo, com mudas produzidas a partir de estacas dos materiais menos suscetíveis e compará-los com os mais suscetíveis em relação à produtividade e qualidade dos frutos.

TABELA 1 - Efeito da concentração de inóculo (conídios/mL) de Septoria passiflorae em seis genótipos de maracujazeiro- azedo. Brasília-DF,2004.

\begin{tabular}{|c|c|c|c|c|c|c|}
\hline \multirow[t]{3}{*}{ Genótipos } & \multicolumn{6}{|c|}{ Severidade (1-5) } \\
\hline & \multicolumn{6}{|c|}{ [conidios/mL] } \\
\hline & {$\left[10^{4}\right]$} & & {$\left[10^{5}\right]$} & & {$\left[10^{6}\right]$} & \\
\hline Yellow Master FB200 & 2,37 & A & 3,58 & $\mathrm{AB}$ & 4,40 & A \\
\hline Yellow Master FB100 & 2,30 & $\mathrm{~A}$ & 3,89 & A & 4,08 & A \\
\hline MAR.20.45 & 2,20 & A & 3,52 & $\mathrm{AB}$ & 4,11 & A \\
\hline MAR.20.31 & 2,10 & A & 3,19 & $\mathrm{BC}$ & 4,06 & A \\
\hline MAR.20.37 & 2,01 & $\mathrm{~A}$ & 3,25 & $\mathrm{BC}$ & 4,27 & A \\
\hline \multirow[t]{2}{*}{ MAR.20.32 } & 1,98 & $\mathrm{~A}$ & 2,97 & $\mathrm{C}$ & 4,04 & A \\
\hline & \multicolumn{6}{|c|}{ Incidência (\%) } \\
\hline MAR.20.31 & 89,58 & $\mathrm{~A}$ & 100 & $\mathrm{~A}$ & 100 & A \\
\hline Yellow Master FB100 & 88,54 & A & 100 & A & 100 & A \\
\hline MAR.20.45 & 87,50 & A & 100 & A & 100 & A \\
\hline Yellow Master FB200 & 86,46 & A & 100 & A & 100 & A \\
\hline MAR.20.32 & 83,34 & $\mathrm{AB}$ & 100 & A & 100 & A \\
\hline \multirow[t]{2}{*}{ MAR.20.37 } & 74,59 & $\mathrm{~B}$ & 100 & A & 100 & $\mathrm{~A}$ \\
\hline & \multicolumn{6}{|c|}{ Desfolha (\%) } \\
\hline Yellow Master FB200 & 29,21 & A & 52,32 & $\mathrm{AB}$ & 71,24 & A \\
\hline Yellow Master FB100 & 27,38 & A & 59,20 & A & 64,98 & A \\
\hline MAR.20.45 & 25,20 & A & 48,89 & $\mathrm{ABC}$ & 64,99 & A \\
\hline MAR.20.31 & 22,39 & A & 41,60 & $\mathrm{BC}$ & 63,36 & A \\
\hline MAR.20.32 & 21,04 & A & 36,30 & $\mathrm{C}$ & 62,30 & A \\
\hline MAR.20.37 & 20,12 & $\mathrm{~A}$ & 42,33 & $\mathrm{BC}$ & 66,64 & $\mathrm{~A}$ \\
\hline
\end{tabular}

Médias seguidas por letras distintas diferem entre si (Tukey, $\mathrm{P}=5 \%$ ). Severidade de doença ( $\mathrm{S}$ ) = 1- Plantas sem sintomas; 2- Lesões esparsas nas folhas tomando até $10 \%$ do limbo foliar; 3- Lesões coalescentes tomando entre $10 \%$ e $33 \%$ do limbo foliar; 4- Lesões coalescentes tomando mais de $33 \%$ do limbo foliar; 5- Desfolha. 
TABELA 2 - Reação (Severidade = S = 1 a 5) à Septoria passiflorae de mudas de genótipos de maracujazeiroazedo cultivadas em casa de vegetação. Brasília-DF, 2004.

\begin{tabular}{|c|c|c|c|c|c|c|c|}
\hline Genótipos & \multicolumn{2}{|c|}{ S (1-5) } & Reação & Genótipo & \multicolumn{2}{|c|}{ S (1-5) } & Reação \\
\hline MAR.20.59 & 4,49 & $\mathrm{~A}$ & AS & MAR.20.07 & 3,93 & D-R & $\mathrm{S}$ \\
\hline MAR.20.48 & 4,45 & $\mathrm{AB}$ & AS & MAR.20.46 & 3,92 & E-R & $\mathrm{S}$ \\
\hline MAR.20.42 & 4,41 & A-C & AS & MAR.20.22 & 3,89 & F-R & $\mathrm{S}$ \\
\hline PES.07 & 4,33 & A-D & AS & PES.09 & 3,88 & F-R & $\mathrm{S}$ \\
\hline MAR.20.11 & 4,30 & A-E & $\mathrm{AS}$ & MAR.2.140 & 3,86 & F-R & $\mathrm{S}$ \\
\hline MAR.20.02 & 4,26 & A-F & AS & MAR.20.23 & 3,86 & F-R & $\mathrm{S}$ \\
\hline MAR.20.43 & 4,23 & A-G & AS & EC.3.0 & 3,84 & G-R & $\mathrm{S}$ \\
\hline MAR.20.09 & 4,19 & A-H & AS & EC.7.L & 3,84 & G-R & $\mathrm{S}$ \\
\hline MAR.20.25 & 4,19 & $\mathrm{~A}-\mathrm{H}$ & AS & MAR.20.19 & 3,84 & G-R & $\mathrm{S}$ \\
\hline MAR.20.12 & 4,18 & A-I & $\mathrm{AS}$ & MAR.20.35 & 3,84 & G-R & $\mathrm{S}$ \\
\hline MAR.20.18 & 4,17 & A-J & AS & MAR.20.01 & 3,82 & G-R & $\mathrm{S}$ \\
\hline MAR.20.04 & 4,17 & A-J & AS & Yellow Master FB100 & 3,81 & $\mathrm{H}-\mathrm{S}$ & $\mathrm{S}$ \\
\hline MAR.20.39 & 4,15 & A-K & AS & MAR.20.26 & 3,81 & $\mathrm{H}-\mathrm{S}$ & $\mathrm{S}$ \\
\hline Redondão & 4,14 & A-K & AS & MAR.20.17 & 3,77 & $\mathrm{I}-\mathrm{S}$ & $\mathrm{S}$ \\
\hline MAR.20.21 & 4,13 & A-K & AS & MAR.20.38 & 3,76 & $\mathrm{~J}-\mathrm{S}$ & $\mathrm{S}$ \\
\hline MAR.20.45 & 4,12 & A-K & AS & MAR.20.40 & 3,74 & $\mathrm{~K}-\mathrm{S}$ & $\mathrm{S}$ \\
\hline MAR.20.08 & 4,12 & A-K & AS & MAR.20.30 & 3,74 & $\mathrm{~K}-\mathrm{S}$ & $\mathrm{S}$ \\
\hline MAR.20.16 & 4,10 & A-L & AS & Yellow Master FB200 & 3,70 & L-S & $\mathrm{S}$ \\
\hline MAR.20.15 & 4,08 & A-M & AS & MAR.20.44 & 3,69 & L-S & $\mathrm{S}$ \\
\hline MAR.20.41 & 4,08 & A-M & AS & MAR.20.28 & 3,68 & M-S & $\mathrm{S}$ \\
\hline MAR.20.13 & 4,08 & A-M & AS & MAR.20.06 & 3,68 & M-S & $\mathrm{S}$ \\
\hline MAR.20.37 & 4,07 & B-N & AS & MAR.20.24 & 3,68 & M-S & $\mathrm{S}$ \\
\hline MAR.20.20 & 4,07 & B-N & AS & MAR.20.33 & 3,67 & $\mathrm{~N}-\mathrm{S}$ & $\mathrm{S}$ \\
\hline MAR.20.47 & 4,06 & B-N & AS & MAR.20.29 & 3,62 & $\mathrm{O}-\mathrm{S}$ & $\mathrm{S}$ \\
\hline MAR.20.50 & 4,02 & $\mathrm{C}-\mathrm{O}$ & AS & EC.2.0 & 3,61 & $\mathrm{O}-\mathrm{S}$ & $\mathrm{S}$ \\
\hline MAR.20.32 & 4,00 & C-P & $\mathrm{S}$ & MAR.20.34 & 3,60 & P-S & $\mathrm{S}$ \\
\hline MAR.20.03 & 3,97 & $\mathrm{D}-\mathrm{Q}$ & $\mathrm{S}$ & MAR.20.10 & 3,57 & Q-S & $\mathrm{S}$ \\
\hline MAR.20.05 & 3,96 & D-Q & $\mathrm{S}$ & MAR.20.36 & 3,55 & $\mathrm{RS}$ & $\mathrm{S}$ \\
\hline MAR.20.49 & 3,95 & D-R & $\mathrm{S}$ & Joseph & 3,54 & $\mathrm{RS}$ & $\mathrm{S}$ \\
\hline MAR.20.31 & 3,95 & D-R & $\mathrm{S}$ & MAR.20.27 & 3,40 & $\mathrm{~S}$ & $\mathrm{~S}$ \\
\hline
\end{tabular}

${ }^{1}$ Índice de severidade de doença (ISD): 1- Plantas sem sintomas; 2- Lesões esparsas nas folhas tomando até 10\% do limbo foliar; 3- Lesões coalescentes tomando entre $10 \%$ e $33 \%$ do limbo foliar; 4- Lesões coalescentes tomando mais de $33 \%$ do limbo foliar; 5 Desfolha. ${ }^{2}$ Médias seguidas por letras distintas diferem entre si (Tukey, $\mathrm{P}=5 \%$ ). Em função do ISD, considerou-se: resistentes (R) os genótipos com médias entre 1 e 2; medianamente resistentes (MR) com médias entre 2 e 3; suscetíveis (S) com médias entre 3 e 4; e altamente suscetíveis (AS) com médias maiores que 4.

\section{CONCLUSÕES}

1-Os genótipos MAR.20.27 e MAR.20.59 apresentaram menores valores de severidade de doença e desfolha.

2-Os genótipos MAR.20.59, MAR.20.48 e MAR.20.42 apresentaram maior severidade de doença.

\section{AGRADECIMENTOS}

À CAPES e ao CNPq, pela concessão de bolsas e apoio à infraestrutura do Departamento de Fitopatologia da Universidade de Brasília e da Embrapa Cerrados.

\section{REFERÊNCIAS}

AMATA, R.L.; OTIPA, M.J.; WAIGANJO, M.; WABULE, M.; THURANIRA, E.G. ERBAUGH, M.; MILLER, S. Incidence, prevalence and severity of passion fruit fungal diseases in major production regions of Kenya. Journal of Applied Biosciences, West Lafayette v. 20, p. 1146-1152. 2009. 
BOUZA, R.B. Reação em progênies de maracujáazedo à antracnose, septoriose, cladosporiose e bacteriose em condições de campo e casa de vegetação. 2009. 160 f. Dissertação (Mestrado em Fitopatologia) - Universidade de Brasília, Brasília. 2009.

BUENO, P.A.O.; PEIXOTO, J.R.; JUNQUEIRA, N.T.V.; MATTOS, J.K.A. Incidência e severidade de septoriose (Septoria passiflorae Sydow) em mudas de 48 genótipos de maracujazeiro-azedo, sob casa de vegetação no Distrito Federal. Bioscience Journal, Uberlândia, v. 23, n. 2, p. 88-95. 2007.

COIMBRA, K.G. Desempenho agronômico de progênies de maracujazeiro-azedo no Distrito Federal. 2010. 125 f. Dissertação (Mestrado em Agronomia) - Universidade de Brasília, Brasília, 2010.

DIAS, S. C. Morte precoce do maracujazeiroamarelo (Passiflora edulis f. flavicarpa) causada por patógenos que afetam a parte aérea da planta. Dissertação (Mestrado em Fitopatologia)- Universidade de Brasília, Brasília, 1990. 137p.

EL-MOOR, R.D. Melhoramento genético do maracujazeiro-azedo (Passiflora edulis Sims f. flavicarpa Deg) visando à resistência ao nematóide de galhas do gênero Meloidogyne spp. 2002. Dissertação (Mestrado) - Universidade de Brasília, Brasília, 2002.
FISCHER, I.H.; REZENDE, J.A.M. Diseases of passion flower (Passiflora spp.). Pest Technology, Chaveland, v. 2, n. 1, p. 1-19. 2008.

JUNQUEIRA, N.T.V.; DOS ANJOS, J.R.N.; SILVA, A.P.O.; CHAVES, R.C.; GOMES, A.C. Reação às doenças e produtividade de onze cultivares de maracujá-azedo cultivadas sem agrotóxicos. Pesquisa Agropecuária Brasileira, Brasília, v. 38, n. 8, p. 1005-1010, 2003.

NASCIMENTO, A.C.; JUNQUEIRA, N.T.V.; PEIXOTO, J.R.; MANICA, I.; KOSOSK, R.M.; JUNQUEIRA, K.P. Comportamento de frutos de 10 genótipos de maracujazeiro-azedo em relação à antracnose (Colletrotrichum gloeosporioides ) e a verrugose (Cladosporium spp.) no Distrito Federal. In: CONGRESSO BRASILEIRO DE FRUTICULTURA, 16., 2000. Fortaleza. Anais... p. 473.

PINTO, P.H.D. Reação de genótipos de maracujáazedo (Passiflora edulis f. flavicarpa Degener) ao vírus Pasionfruit Woodiness Virus (PWV) e ao fungo Septoria passiflorae. Dissertação (Mestrado) - Universidade de Brasília, Brasília, 2002.

SOUSA, M.A.F. Produtividade e reação de progênies de maracujazeiro-azedo a doenças em campo e casa de vegetação. 2009. 248f. Tese (Doutorado em Fitopatologia) - Universidade de Brasília, Brasília, 2009. 